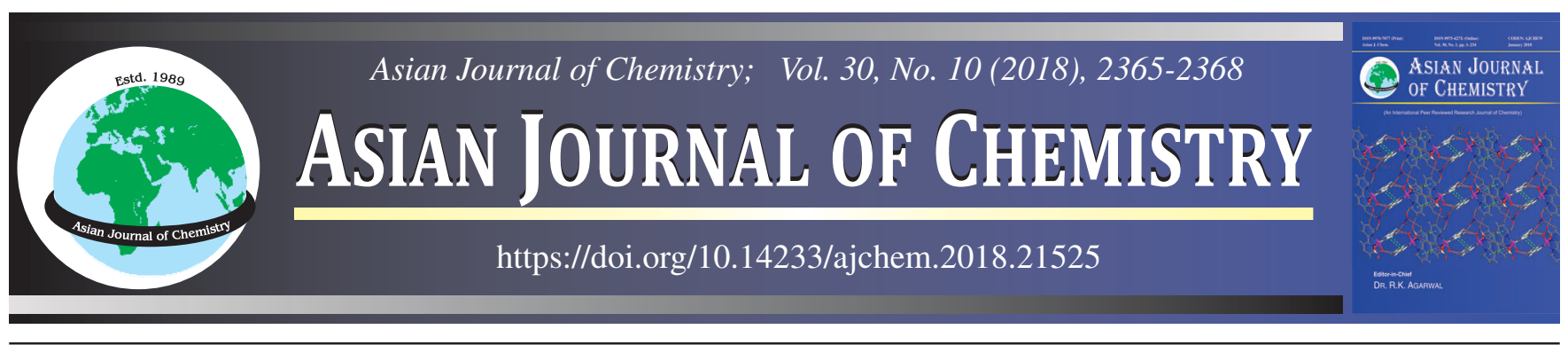

\title{
Synthesis, Characterization and Antifungal Activities of Some Novel Mixed Ligand Complexes of Manganese(III) $\gamma$-Diketone
}

\author{
Priti Dubey and Sudha Yadava*
}

Department of Chemistry, Deen Dayal Upadhyay Gorakhpur University, Gorakhpur-273 009, India

*Corresponding author: E-mail: dr_sudhayadava@yahoo.co.in

Received: 16 June 2018;

Accepted: 6 August 2018;

Published online: 31 August 2018;

AJC-19076

A novel series of manganese(III) mixed ligand complexes containing $\gamma$-diketone (hexane-2,5-dione) and ethylenediamine have been synthesized, that are high-spin complexes with general formula [Mn( $\gamma$-diketone) $\left.{ }_{2} \mathrm{X}(\mathrm{en})\right]$; where $\gamma$-diketone is hexane 2,5-dione (hdo); $\mathrm{X}$ $=\mathrm{Cl}^{-}, \mathrm{Br}^{-}, \mathrm{N}_{3}{ }^{-}$or $\mathrm{NCS}^{-}$and en = ethylenediamine. All these complexes have been characterized using UV-visible, FT-IR, ESI-MS spectra, elemental analyses, molar conductance studies and magnetic susceptibility measurements. The tentative structures for all the four complexes have been proposed to be octahedral. The $\left[\mathrm{Mn}(\mathrm{hdo})_{2} \mathrm{NCS}(\mathrm{en})\right]$ and $\left[\mathrm{Mn}(\mathrm{hdo})_{2} \mathrm{Cl}(\mathrm{en})\right]$ show pronounced antifungal activity towards Aspergillus niger, Aspergillus flavus and Aspergillus terreus fungal species.

Keywords: $\mathrm{Mn}(\mathrm{III})$ mixed ligand complexes, $\gamma$-Diketone, Ethylenediamine, Magnetic susceptibility, Antifungal activity.

ᄂ _ - - - - - - - - - - - - - - - - - - - - - - - - - - -

\section{INTRODUCTION}

Manganese has significant chemical and biological importances [1-7]. This is supported the global research interests in the studies of Mn(III) complexes [8-13]. Wide variety of high spin $\mathrm{Mn}(\mathrm{III})$ octahedral complexes are reported in literature [14-18]. Manganese(III) $\beta$-diketone complexes shows versatile catalytic behaviour [19-24] and are also used in the depolymerization of coal using humic acid, as a coal model compound [23] which has been tested by viscosity measurement method. Mixed ligand complexes of Mn(III) $\beta$-diketone play an important role in antibacterial, antifungal and antioxidant activities [23-25]. Keeping in view, the applications of Mn(III) $\beta$-diketone complexes that have gained the interest we have chosen $\gamma$-diketone ligand. The complexes of $\gamma$-diketone with transition as well as rare earth metals have not been yet reported in literature. This communication reports the synthesis, characterizations and antifungal activities of mixed ligand complexes of $\mathrm{Mn}$ (III) specially with $\gamma$-diketone.

\section{EXPERIMENTAL}

All the chemicals were used of reagent grade (S.D fine) and hexane 2,5-dione (hdo) (Sigma Aldrich, USA), used as purchased. The molar conductance measurements of the synthesized complexes were measured in acetic acid at room temperature using Automatic conductivity/TDS meter TCM 15+. Electronic spectra were recorded on a Hitachi (Japan) spectrophotometer (model U-2900) from 300 to $800 \mathrm{~nm}$, using dilute acetic acid as a solvent. FT-IR spectra were recorded on a spectrophotometer (Perkin Elmer Spectrum II) using potassium bromide pellets $\left(4000-450 \mathrm{~cm}^{-1}\right)$. ESI-MS was done on mass spectrometer (WATERS Q-TOF PREMEIR-HAB213) using (acetonitrile-methanol-DMSO) as the solvent. Magnetic susceptibility measurements were obtained at room temperature on vibrating sample magnetometer. Elemental analyses were carried out on elemental analyzer (Eurovector EA 3000).

Preparation of thiocyanatobis(hdo)manganese(III) ethylenediamine: $2 \mathrm{~g}(0.005 \mathrm{~mol})$ powder thiocyanatobis(hdo) manganese(III) [26] was refluxed with $1.5 \mathrm{~mL}$ of ethylenediamine for $20 \mathrm{~h}$. After refluxing the product was cooled for $1 \mathrm{~h}$ at room temperature resulting dark brown-black shining crystal of thiocyanatobis(hdo)Mn(III) ethylenediamine which were obtained in pure form and finally dried in electric oven over $\mathrm{P}_{2} \mathrm{O}_{5}$, $1.5 \mathrm{~g}(42.45 \%)$, m.p. $160^{\circ} \mathrm{C}$, anal. calcd. (\%) for $\mathrm{C}_{15} \mathrm{H}_{28} \mathrm{~N}_{3} \mathrm{O}_{4} \mathrm{SMn}$; C, 35.87; H, 6.97; N, 10.96; S, 7.97; O, 15.94; Mn, 22.78.

Preparation of azidobis(hdo)manganese(III)ethylenediamine: $2 \mathrm{~g}$ (0.006 mol) azidobis(hdo)manganese(III) [26] was refluxed with $1.5 \mathrm{~mL}$ of ethylenediamine for $20 \mathrm{~h}$. After

This is an open access journal, and articles are distributed under the terms of the Creative Commons Attribution-NonCommercial 4.0 International (CC BY-NC 4.0) License, which allows others to copy and redistribute the material in any medium or format, remix, transform, and build upon the material, as long as appropriate credit is given and the new creations are licensed under the identical terms. 
refluxing the product was cooled for $1 \mathrm{~h}$ at room temperature resulting dark black shining crystal of azidobis(hdo)Mn(III) ethylenediamine which were obtained in pure form and finally dried in electric oven over $\mathrm{P}_{2} \mathrm{O}_{5} .1 .5 \mathrm{~g}(34.20 \%)$, m.p. $162{ }^{\circ} \mathrm{C}$, anal. calcd. (\%) for $\mathrm{C}_{14} \mathrm{H}_{28} \mathrm{~N}_{5} \mathrm{O}_{4} \mathrm{Mn} ; \mathrm{C}, 43.50 ; \mathrm{H}, 7.25 ; \mathrm{N}, 18.12$; O, 16.57; Mn, 14.24.

Preparation of chlorobis(hdo)manganese(III)ethylenediamine: It was prepared by the refluxion of $2 \mathrm{~g}(0.006 \mathrm{~mol})$ chloroobis(hdo)manganese(III) [26] and $2 \mathrm{~mL}$ of ethylenediamine as above mention method. 1.5g (33.30 \%), m.p. 164 ${ }^{\circ} \mathrm{C}$, anal. calcd.(\%) for $\mathrm{C}_{14} \mathrm{H}_{28} \mathrm{~N}_{2} \mathrm{O}_{4} \mathrm{ClMn} ; \mathrm{C}, 44.38 ; \mathrm{H}, 7.39$; N, 7.39; O, 16.90; Cl, 9.37; Mn, 14.57.

Preparation of bromobis(hdo)manganese(III) ethylenediamine: For the preparation of bromobis(hdo)manganese(III) ethylenediamine, $2 \mathrm{~g}$ (0.005 mol) of bromobis(hdo)manganese(III) [26] was refluxed with $1.5 \mathrm{~mL}$ of ethylenediamine for $20 \mathrm{~h}$ as above mentioned method. $1.5 \mathrm{~g}(33.81 \%)$, m.p. $165^{\circ} \mathrm{C}$, anal. calcd. (\%) for $\mathrm{C}_{14} \mathrm{H}_{28} \mathrm{~N}_{2} \mathrm{O}_{4} \mathrm{BrMn} ; \mathrm{C}, 39.81 ; \mathrm{H}, 6.63 ; \mathrm{N}, 6.63$; $\mathrm{O}, 15.16 ; \mathrm{Br}, 18.72 ; \mathrm{Mn}, 13.03$.

Antifungal activity and MIC: Poisoned food technique [26a] was used to check the in vitro antifungal activity and MIC of the $\left.\mathrm{Mn}(\mathrm{hdo})_{2} \mathrm{NCS}(\mathrm{en})\right]$ and $\left[\mathrm{Mn}(\mathrm{hdo})_{2} \mathrm{Br}(\mathrm{en})\right]$ complex against three fungal strain i.e. A. terreus, A. flavus, A. niger [23]. All fungi were cultivated in Potato Dextrose Agar (Merck). The solution of the complex was poured into sterilized Petri dish and was left to solidify. The spores of these fungi were inoculated at the centre of the solidified medium in Laminar Chamber and finally the dish was incubated at $37^{\circ} \mathrm{C}$ for $72 \mathrm{~h}$ and then the treated petri dish were compared with controlled petri plates. The experiment was carried out in duplicates.

\section{RESULTS AND DISCUSSION}

All these synthesized complexes are quite stable at room temperature when stored over $\mathrm{P}_{2} \mathrm{O}_{5}$. They are sparingly soluble in DMSO and completely soluble in acetic acid. The general reaction for the preparation of these $\mathrm{Mn}$ (III) substituted complex with ethylenediamine ligand may be given as fallows:

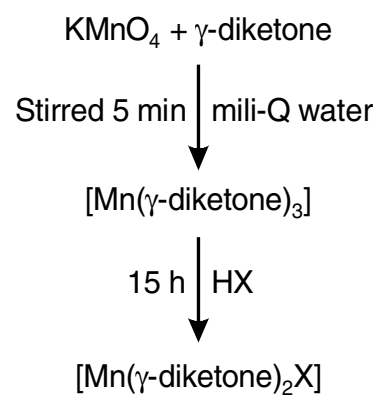

where $\gamma$-diketone $=$ hexane 2,5 -dione $\mathrm{X}=\mathrm{Cl}^{-}, \mathrm{Br}^{-}, \mathrm{NCS}^{-}$or $\mathrm{N}_{3}^{-}$
These $\left[\mathrm{Mn}(\gamma \text {-diketone })_{2} \mathrm{X}\right]$ complex were refluxed with ethylenediamine to give final product. The proposed reaction scheme may be given as:

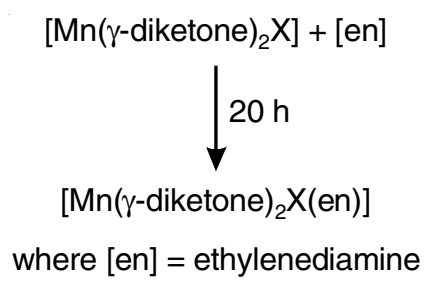

The elemental analysis of these complexes suggest 2:1 (metal:ligand) stiochiometry while the molecular weight suggest the dimeric nature. The molar conductance values in acetic acid with $10^{-3} \mathrm{~mol} \mathrm{~L}^{-1}$ concentration are in the range 12$26 \Omega^{-1} \mathrm{~cm}^{2} \mathrm{~mol}^{-1}$, indicating non-electrolytic nature [27]. The physical properties of these complexes have been given in Table-1.

The most advantageous technique to study the Mn(III) complexes is UV-visible spectroscopy. The electronic spectra of all these novel $\mathrm{Mn}$ (III) complexes exhibit bands in the region of $18000-22000 \mathrm{~cm}^{-1}$ (Fig. 1) attributing to ${ }^{5} \mathrm{~T}_{2 \mathrm{~g}} \rightarrow{ }^{5} \mathrm{E}_{\mathrm{g}}$ transitions suggesting octahedral geometry for these $\mathrm{Mn}$ (III) complexes [23].

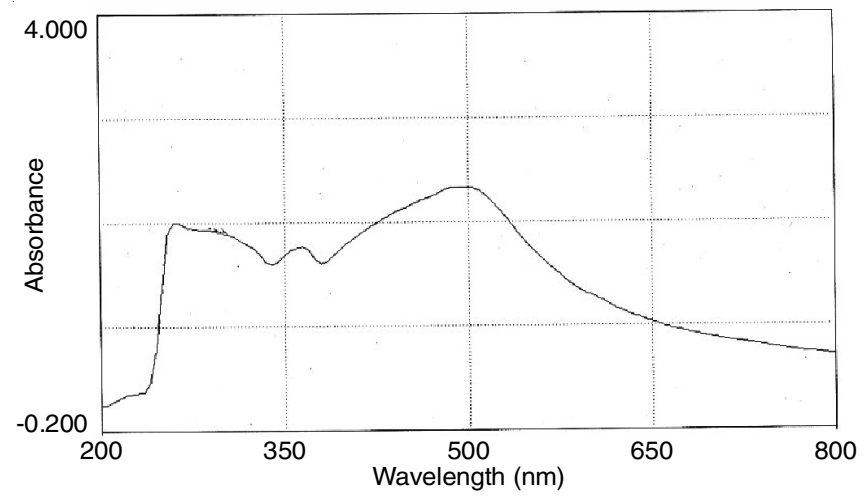

Fig. 1a. UV-spectra of [Mn(hdo $)_{2} \operatorname{Br}($ en $\left.)\right]$ in $200-800 \mathrm{~nm}$ range

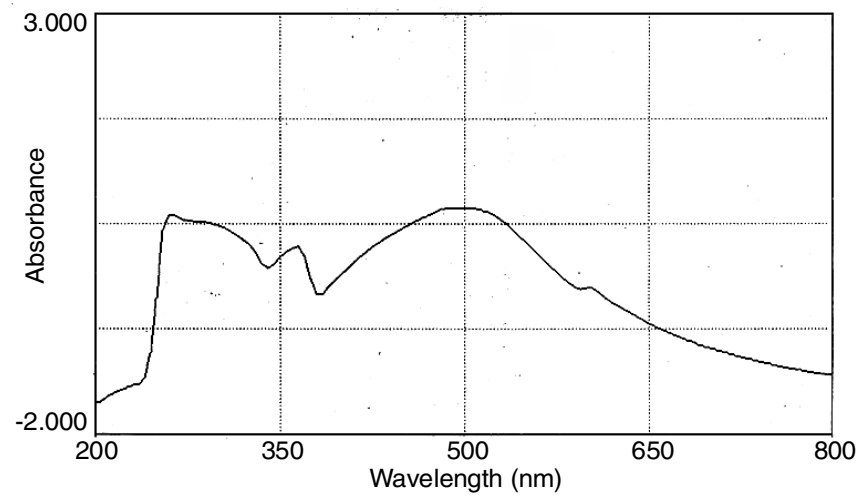

Fig. 1b. UV-spectra of $\left[\mathrm{Mn}(\mathrm{hdo})_{2} \mathrm{Cl}(\mathrm{en})\right]$ in $200-800 \mathrm{~nm}$ range

\begin{tabular}{lccccc}
\multicolumn{7}{c}{ TABLE-1 } \\
& PHYSICO-ANALYTICAL DATA OF COMPLEXES & \\
\hline \multicolumn{1}{c}{ Complexes } & Colour & $\mu_{\text {eff }}(\mathrm{BM})$ & $\begin{array}{c}\text { Molar conductance } \\
\left(\Omega^{-1} \mathrm{~cm}^{2} \text { mol }^{-1}\right)\end{array}$ & Yield $(\%)$ & Formula mass \\
\hline$\left[\mathrm{Mn}(\mathrm{hdo})_{2} \mathrm{NCS}(\mathrm{en})\right]$ & Brown & 4.91 & 12 & 42.45 & 401 \\
{$\left[\mathrm{Mn}(\mathrm{hdo})_{2} \mathrm{~N}_{3}(\mathrm{en})\right]$} & Black & 4.93 & 18 & 34.20 & 386 \\
{$\left[\mathrm{Mn}(\mathrm{hdo})_{2} \mathrm{Cl}(\mathrm{en})\right]$} & Black & 4.90 & 20 & 33.30 & 378 \\
{$\left[\mathrm{Mn}(\mathrm{hdo})_{2} \mathrm{Br}(\mathrm{en})\right]$} & Black & 4.98 & 26 & 33.81 & 422 \\
\hline
\end{tabular}


TABLE-2

SELECTED VIBRATIONAL FREQUENCIES $\left(\mathrm{cm}^{-1}\right)$ IN IR SPECTRA OF Mn(III) $\gamma$-DIKETONE MIXED LIGAND COMPLEXES

\begin{tabular}{ccccc}
\hline$\left[\mathrm{Mn}(\mathrm{hdo})_{2} \mathrm{NCS}(\mathrm{en})\right]$ & {$\left[\mathrm{Mn}(\mathrm{hdo})_{2} \mathrm{~N}_{3}(\mathrm{en})\right]$} & {$\left[\mathrm{Mn}(\mathrm{hdo})_{2} \mathrm{Cl}(\mathrm{en})\right]$} & {$\left[\mathrm{Mn}(\mathrm{hdo})_{2} \mathrm{Br}(\mathrm{en})\right]$} & Assignment \\
\hline 1118 & 1067 & 1083 & 1010 & $v(\mathrm{C}-\mathrm{N})_{\text {Str }}$ \\
3246 & 3240 & 3248 & 3280 & $v\left(\mathrm{NH}_{2}\right)_{\mathrm{Coordinated}}$ \\
3407 & 3410 & 3430 & 619 & $v\left(\mathrm{NH}_{2}\right)_{\text {uncoordinated }}$ \\
608 & 609 & 617 & 1661 & $v(\mathrm{Mn}-\mathrm{O})$ \\
1664 & 1664 & 1660 & - & $v(\mathrm{C}=\mathrm{O})$ \\
2080 & - & - & - & $v(\mathrm{NCS})$ \\
863 & - & - & - & $v(\mathrm{C}-\mathrm{S})$ \\
- & 1217 & 717 & - & $v\left(\mathrm{~N}_{3}\right)$ \\
- & - & - & 592 & $v(\mathrm{Cl})$ \\
& - & & $v(\mathrm{Br})$ & \\
\hline
\end{tabular}

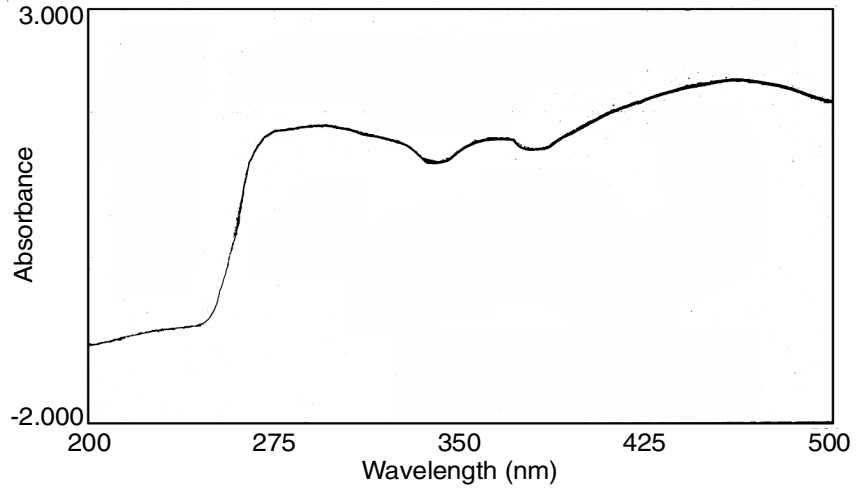

Fig. 1c. UV-spectra of $\left[\mathrm{Mn}(\mathrm{hdo})_{2} \mathrm{~N}_{3}\right.$ (en) $]$ in $200-800 \mathrm{~nm}$ range

The ligand field parameters, i.e. $10 \mathrm{Dq}, \mathrm{B}$ and $\beta$, have also been calculated for these novel complexes. The values of $10 \mathrm{Dq}$ have been calculated from $\lambda_{\max }$ at maximum absorbance. The value of B has been calculated by using the formula $\mathrm{Dq} / \mathrm{B}=$ 2.7 using the Tanabe-Sugano diagram, while $\beta$ has been calculated using the formula:

$$
\beta=\mathrm{B}_{\text {in complex }} / \mathrm{B}_{\text {Free ion }}
$$

The values of $\mathrm{B}$ are lower than that of free ion value for $\mathrm{Mn}(\mathrm{III})\left(1140 \mathrm{~cm}^{-1}\right)$ [28] indicating covalent metal ligand bonds, with the covalency factor $\beta$.

Infrared spectra of all the four novel complexes of Mn(III) with $\gamma$-diketone show one strong peak in the range of 1664$1661 \mathrm{~cm}^{-1}$ corresponding to the coordinated $v(\mathrm{C}=\mathrm{O})$ bond [29]. This band appears after the coordination of $\gamma$-diketone ligand through oxygen donor atom with $\mathrm{Mn}(\mathrm{III})$. Another sharp band in the range of $683-617 \mathrm{~cm}^{-1}$ shows the $v(\mathrm{Mn}-\mathrm{O})$ band, suggesting the coordination of $\mathrm{Mn}$ (III) with mono negative $\gamma$-diketone ligand [30].

The spectra of thiocyanato complex shows two characteristic bands for coordinated $\mathrm{NCS}^{-}$i.e. $\mathrm{v}(\mathrm{C}-\mathrm{N})$ at $2080 \mathrm{~cm}^{-1}$ and $v(\mathrm{C}-\mathrm{S})$ at $863 \mathrm{~cm}^{-1}$ suggesting coordination of $\mathrm{NCS}^{-}$complex through $\mathrm{N}$ atom [31] in the thiocyanato complex. A strong band appears at $1217 \mathrm{~cm}^{-1}$ in case of azido complex that is assigned to the stretching vibration for azido group present in the complex [32]. The spectra of the chloro complex exhibits a significant band at $717 \mathrm{~cm}^{-1}$ assigned to $\mathrm{v}(\mathrm{Cl})$, while bromo substituted complex exhibits a significant band at $592 \mathrm{~cm}^{-1}$ due to the stretching vibration of bromo group present in this complex (Table-2).

Two types of $\left(-\mathrm{NH}_{2}\right)$ stretching frequencies are observed for these complexes. The first one is assigned to the coordinated
$\left(-\mathrm{NH}_{2}\right)$ group with the central metal ion and it has been found in the range of 3280-3246 $\mathrm{cm}^{-1}$ [33] while other prominent peak appear in the range of $3480-3460 \mathrm{~cm}^{-1}$ confirming the presence of non coordinated $\left(-\mathrm{NH}_{2}\right)$ group and the monodentate behaviour of the ligand in these novel complexes.

The mass spectra of [Mn(hdo $\left.)_{2} \mathrm{NCS}(\mathrm{en})\right],\left[\mathrm{Mn}(\mathrm{hdo})_{2} \mathrm{~N}_{3}(\mathrm{en})\right]$, $\left[\mathrm{Mn}(\mathrm{hdo})_{2} \mathrm{Cl}(\mathrm{en})\right]$ and $\left[\mathrm{Mn}(\mathrm{hdo})_{2} \mathrm{Br}(\mathrm{en})\right]$ show peaks at $\mathrm{m} / \mathrm{z}$ values 401.4, 386.2378 .8 and 422.3 , respectively, which corresponds to the molecular ion peaks of complexes.

Magnetic susceptibility measurements show that these complexes have $\mu_{\text {eff }}$ values in the range of 4.90-4.98 BM $[34,35]$. The presence of four unpaired electrons indicates high-spin $\mathrm{Mn}(\mathrm{III})$ complexes with ethylenediamine.

Antifungal activity: The $\left[\mathrm{Mn}(\mathrm{hdo})_{2} \mathrm{NCS}(\mathrm{en})\right]$ and $\left[\mathrm{Mn}(\mathrm{hdo})_{2} \mathrm{Br}(\mathrm{en})\right]$ complexes are screened for their fungi toxic properties against three fungal species namely A.niger, A. flavus. A. terreus. The minimum inhibition concentration values of $\left[\mathrm{Mn}(\mathrm{hdo})_{2} \mathrm{NCS}(\mathrm{en})\right]$ complex is $4 \mathrm{ppm}$ for $A$. flavus and A. terreus while $6 \mathrm{ppm}$ for A. niger and the MIC values of $\left[\mathrm{Mn}(\mathrm{hdo})_{2} \mathrm{Cl}(\mathrm{en})\right]$ complex, are $6 \mathrm{ppm}$ for A. flavus and $A$. terreus while $8 \mathrm{ppm}$ for $A$. niger (Table-3). The antifungal results evidently showed that the $\left[\mathrm{Mn}(\mathrm{hdo})_{2} \mathrm{NCS}(\mathrm{en})\right]$ complex is more effective against test fungi than $\left[\mathrm{Mn}(\mathrm{hdo})_{2} \mathrm{Cl}(\mathrm{en})\right]$ complex [23].

\begin{tabular}{cccc}
\multicolumn{4}{c}{ TABLE-3 } \\
MIC VALUE OF [Mn(hdo) ${ }_{2}$ NCS(en)] \\
AND [Mn(hdo) ${ }_{2}$ Cl(en)] COMPLEXES \\
\hline $\begin{array}{c}\text { Concentration of } \\
\text { complexes }\end{array}$ & A. niger & A. flavus & A. terrus \\
\hline$\left[\right.$ Mn(hdo) ${ }_{2}$ NCS(en)] & - & - & - \\
2 & 60.5 & 79.0 & 71.02 \\
4 & 92.0 & $100^{*}$ & $100^{*}$ \\
6 & $100^{*}$ & 100 & 100 \\
8 & 100 & 100 & 100 \\
\hline$\left[\right.$ Mn(hdo) ${ }_{2}$ Cl (en)] & - & - & - \\
2 & 47.6 & 52.0 & 60.31 \\
4 & 51.5 & 67.0 & 69.8 \\
6 & 91.2 & $100^{*}$ & $100^{*}$ \\
8 & $100^{*}$ & 100 & 100 \\
\hline
\end{tabular}

Structure: On the basis of elemental analysis, UV, IR, conductivity measurements, magnetic susceptibility measurements and ESI-mass spectra, the novel four complexes have been proposed to be octahedral (Fig. 2). 

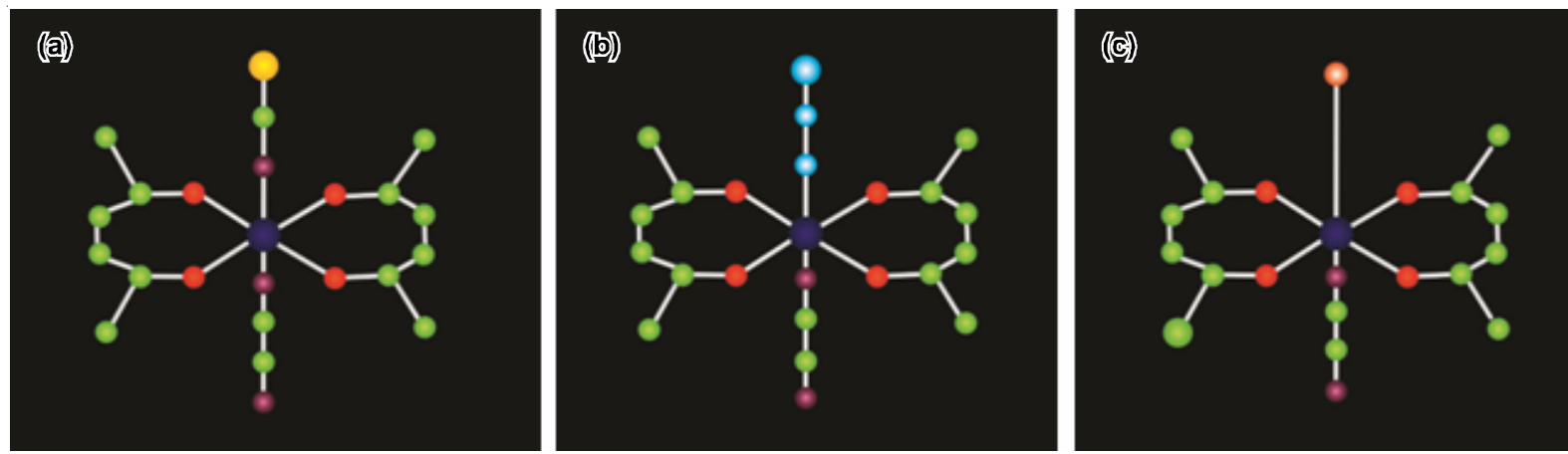

Fig. 2. Structure of (a) $\left[\mathrm{Mn}(\gamma \text {-diketonato })_{2} \mathrm{NCS}(\mathrm{en})\right]$, (b) $\left[\mathrm{Mn}(\gamma \text {-diketonato })_{2} \mathrm{~N}_{3}(\mathrm{en})\right]$ and (c) $\left[\mathrm{Mn}(\gamma \text {-diketonato })_{2} \mathrm{X}(\mathrm{en})\right]$

\section{Conclusion}

This manuscript present the synthesis characterization and antifungal activities of novel $\mathrm{Mn}$ (III) $\gamma$-diketone mixed ligand complexes. The IR spectra of these complexes show all the relevant peaks which confirms the formation these complexes. Octahedral structure for all the four novel complexes has been suggested on the basis of spectrochemical studies. The antifungal studies have shown that $\left[\mathrm{Mn}(\mathrm{hdo})_{2} \mathrm{NCS}(\mathrm{en})\right]$ complex is more effective against test fungi than [Mn(hdo $\left.)_{2} \mathrm{Cl}(\mathrm{en})\right]$ complex [23].

\section{ACKNOWLEDGEMENTS}

The authors are also grateful to The Head, Department of Chemistry, Deen Dayal Upadhyay Gorakhpur University, Gorakhpur, India for providing all necessary facilities for the work. The authors acknowledge to CDRI Lucknow, IIT Kanpur and STIC Cochin, India for different analytical analyses. Thanks are also due to Department of Botany, Deen Dayal Upadhyay Gorakhpur University, Gorakhpur, India for providing facilities for antifungal studies.

\section{CONFLICT OF INTEREST}

The authors declare that there is no conflict of interests regarding the publication of this article.

\section{REFERENCES}

1. K. Das, A. Datta, B. B. Beyene, C. Massera, E. Garribba, C. Sinha, T. Akitsu and S. Tankae, Polyhedron, 127, 315 (2017); https://doi.org/10.1016/j.poly.2017.02.017.

2. J.E. Kostka, G.W. Luther III and K.H. Nealson, Geochim. Cosmochim. Acta, 59, 894 (1995);

https://doi.org/10.1016/0016-7037(95)00007-0.

3. S.G. Silva, J.A. Nobrega and F.R.P. Rocha, Microchem. J., 98, 109 (2011); https://doi.org/10.1016/j.microc.2010.12.004.

4. D.G. Kehres and M.E. Maguire, FEMS Microbiol. Rev., 27, 263 (2003); https://doi.org/10.1016/S0168-6445(03)00052-4.

5. T. Yagyu, K. Yano, T. Kimata and K. Jitsukawa, Organometallics, 28, 2342 (2009); https://doi.org/10.1021/om900007b.

6. D.F. Leto and T.A. Jackson, J. Biol. Inorg. Chem., 19, 1 (2014); https://doi.org/10.1007/s00775-013-1067-4.

7. G. Christou, Acc. Chem. Res., 22, 328 (1989); https://doi.org/10.1021/ar00165a006.

8. M.N. Bhattacharjee, M.K. Chaudhuri and D.T. Khathing, Dalton Trans., 669 (1982); https://doi.org/10.1039/dt9820000669.

9. M. Damercheli, D. Dayyani, M. Behzad, B. Mehravi and M.S. Ardestani J. Coord. Chem., 68, 1500 (2015); https://doi.org/10.1080/00958972.2015.1027697.

10. S. Yadava and S.L. Bharati, J. Coord. Chem., 64, 3950 (2011); https://doi.org/10.1080/00958972.2011.632412.

11. S.L. Bharati and S. Yadava, J. Coord. Chem., 65, 3492 (2012); https://doi.org/10.1080/00958972.2012.718763.
12. K. Barnese, E.B. Gralla, J.S. Valentine and D.E. Cabelli, Proc. Natl. Acad. Sci. USA, 109, 6892 (2012); https://doi.org/10.1073/pnas.1203051109.

13. S. Kumar, E.J. Newmann, J.B. Sortais, K. Junge, C. Darcel and M. Beller, Nature Commun., 7, 12641 (2016); https://doi.org/10.1038/ncomms12641.

14. V.W. Day, B.R. Stults, E.L. Tasset, R.O. Day and R.S. Marianelli, J. Am. Chem. Soc., 96, 2650 (1974); https://doi.org/10.1021/ja00815a075.

15. R. Freitag and J. Conradie, J. Chem. Educ., 90, 1692 (2013); https://doi.org/10.1021/ed400370p.

16. P.L.W. Tregenna-Piggott, Inorg. Chem., 47, 448 (2008); https://doi.org/10.1021/ic700968q.

17. B.R. Stults, R.S. Marianelli and V.W. Day, Inorg. Chem., 18, 1853 (1979); https://doi.org/10.1021/ic50197a028.

18. R. Freitag, T.J. Muller and J. Conradie, J. Chem. Crystallogr., 44, 352 (2014); https://doi.org/10.1007/s10870-014-0522-6.

19. W.R. Cullen and E.B. Wickenheiser, J. Organomet. Chem., 370, 141 (1989); https://doi.org/10.1016/0022-328X(89)87281-X.

20. A. Sudo, S. Hirayama and T. Endo, J. Polym. Sci. A: Polym. Chem., 48, 479 (2010); https://doi.org/10.1002/pola.23810.

21. M.J. Rodriguez- Douton, M. Isabel Fernandez, A.M. Gonzalez-Noya, M. Mareiro, R. Pedrido and M.J. Romero, Synth. React. Inorg. Met.-Org. Nano-Met. Chem., 36, 655 (2006); https://doi.org/10.1080/15533170600962430.

22. F.D. Lewis, A.M. Miller and G.D. Salvi, Inorg. Chem., 34, 3173 (1995); https://doi.org/10.1021/ic00116a007.

23. Y.-F. Wang, K.K. Toh, E.P.J. Ng and S. Chiba, J. Am. Chem. Soc., 133, 6411 (2011) https://doi.org/10.1021/ja200879w.

24. Y.-F. Wang and S. Chiba, J. Am. Chem. Soc., 131, 12570 (2009) https://doi.org/10.1021/ja905110c.

25. B.A. Malik and J.M. Mir, J. Coord. Chem., 71, 104 (2018); https://doi.org/10.1080/00958972.2018.1429600.

26. K. Isobe and S. Kawaguchi, Bull. Chem. Soc. Jpn., 48, 250 (1975); https://doi.org/10.1246/bcsj.48.250.

27. S.F.A. Kettle, Coordination Compounds, Thomas Nelson and Sons, The Press: London, p. 168 (1975).

28. J.E. Huheey, E.A. Keiter and R.L. Keiter, Inorganic Chemistry, Principles of Structure and Reactivity, Pearson Education: Singapore, edn 4, p. 445 (2005).

29. G. Newman and D.B. Powell, J. Am. Chem. Soc., 0, 3447 (1962); https://doi.org/10.1039/JR9620003447.

30. H. Visser, C.E. Dubé, W.H. Armstrong, K. Sauer and V.K. Yachandra, J. Am. Chem. Soc., 124, 11008 (2002); https://doi.org/10.1021/ja020409j.

31. R.J.H. Clark and C.S. Williams, Spectrochim. Acta, 22, 1081 (1966); https://doi.org/10.1016/0371-1951(66)80198-4.

32. J.R. Dyer, Applications of Absorption Spectroscopy of Organic Compounds, Prentice-Hall of India Private Limited, New Delhi (1969).

33. B.H. Stuart, Infrared Spectroscopy: Fundamentals and Applications, John Wiley \& Sons, Chichester, West Sussex, England, p. 104 (2004).

34. E.B. Fleischer, J.M. Palmer, T.S. Srivastava and A. Chatterjee, J. Am. Chem. Soc., 93, 3162 (1971); https://doi.org/10.1021/ja00742a012.

35. D.V. Behere and S. Mitra, Inorg. Chem., 19, 992 (1980); https://doi.org/10.1021/ic50206a039. 